\title{
Özelleştirilmiş Uygunluk Fonksiyonu Tabanlı Su Döngüsü Algoritması ile PID Parametrelerinin Optimizasyonu*
}

\author{
Harun Gür ${ }^{1}$, Murat Furat ${ }^{2}$ \\ 1 İskenderun Teknik Üniversitesi, Mühendislik ve Doğa Bilimleri Fakültesi, Elektrik ve Elektronik Mühendisliği, Hatay, Türkiye (ORCID: 0000-0003-1291-5972) \\ 2 İskenderun Teknik Üniversitesi, Mühendislik ve Doğa Bilimleri Fakültesi, Elektrik ve Elektronik Mühendisliği, Hatay, Türkiye (ORCID: 0000-0003-3179-5099)
}

(Konferans Tarihi: 5-7 Mart 2020)

(DOI: 10.31590 /ejosat.araconf43)

ATIF/REFERENCE: Gür, H., \& Furat, M. (2020). Özelleştirilmiş Uygunluk Fonksiyonu Tabanlı Su Döngüsü Algoritması ile PID Parametrelerinin Optimizasyonu. Avrupa Bilim ve Teknoloji Dergisi, (Özel Say1), 332-341.

$\ddot{O} \mathbf{z}$

Endüstriyel alanda kullanılan kontrolcüler arasında PID kontrolcü, en yaygın olanıdır. Bunun önemli sebebi olarak bu kontrolcüde kullanılan parametre sayısının az olması ve parametrelerinin her birinin uygulanan sistem çıkışına olan etkisinin ölçülebilir sayılabilir. PID parametreleri, birbirinden bağımsız olup sıfır ile sonsuz aralığında değerler alır. Literatürde, bu konuda yapılan çalışmalar gerek matematiksel modele dayalı gerekse sistemin açık çevrim veya kapalı çevrim çıkışına dayalı yöntemlerden oluşmaktadır. Bu yöntemlerin yanında, meta-sezgisel yöntemler de son yıllarda popüler olarak kullanılmaya başlanmıştır. Bunlar, doğadaki çeşitli olaylardan esinlenilerek hazırlanan optimizasyon yöntemleridir. Bu çalışmada, fizik ve kimya tabanlı olayların matematiksel ifadelerinden yola çıkılarak elde edilen algoritmalardan biri olan Su Döngüsü Algoritması (SDA) kullanılarak optimum PID parametreleri aranmıştır. Geleneksel olarak sadece bir uygunluk fonksiyonu ile arama yapılırken bu çalışmada PID parametrelerinin özelliklerini yansıtan özelleştirilmiş uygunluk fonksiyonları ayrı ayrı kullanılmıştır. Elde edilen sonuçlar grafiksel ve istatistiksel olarak verilmiştir.

Anahtar Kelimeler: Su Döngüsü Algoritması, Meta Sezgisel Algoritma, Optimizasyon, PID, Özelleştrilmiş Uygunluk Fonksiyonu.

\section{Optimization of PID Parameters with Customized Fitness Function Based Water Cycle Algorithm}

\begin{abstract}
Among the controllers used in the industrial field, the PID controller is the most commonly used one. The important reason is that the number of parameters used in this controller is only three and the effect of each of the parameters on the applied system output is measurable. PID parameters are independent from each other and take values between zero and infinity. In the literature, studies on this subject consist of both mathematical model based and open loop or closed loop output methods of the system. In addition to these methods, meta-heuristic methods have also been used in recent years. These are optimization methods prepared by inspiring from various events in nature. In this study, optimum PID parameters were searched using the Water Cycle Algorithm (WCA), one of the algorithms obtained based on the mathematical expressions of physics and chemistry-based events. Instead of searching with only one fitness function, customized fitness functions that reflect the characteristics of PID parameters were used in this study. The results obtained are given graphically and statistically.
\end{abstract}

Keywords: Water Cycle Algorithm, Meta Heuristic Optimization, Optimization, PID, Costimized Fitness Function.

\footnotetext{
* Bu makale International Conference on Access to Recent Advances in Engineering and Digitalization (ARACONF 2020) de sunulmuştur.
} 


\section{Giriş}

Kontrol sistemlerinde kullanılan optimizasyon yöntemleri, istenilen çıkış verilerinin enerji açısından daha verimli daha stabil ve daha hızlı cevap alınabilmesini sağlamaktadır. Kontrol sistemlerinde yapılan optimizasyon için genellikle yapay zeka, matematiksel modelleme yöntemleri, doğadan esinlenerek oluşturulan meta-sezgisel yöntemler (sürü optimizasyon algoritmaları, Biyo-esinlenme algoritmaları, fizik ve kimyasal tabanlı algoritmalar vb.) yöntemler kullanılmaktadır [1].

Bu yaygın kullanılan yöntemler incelendiğinde; yapay zekâ tabanlı yöntemler uzmanlık gerektiren yöntemlerdir. Matematiksel modelleme yöntemleri ise ele alınan sistemin tüm parametrelerini sistem karakteristiğine etkisinin bilinmesi gerektiğinden oldukça karmaşıktır. Ancak her iki yöntemin de olumlu yönü istenilen amaca yönelik iyi sonuçlar alınabilmesidir [1].

Meta sezgisel yöntemlerin en önemli özelliği matematiksel tabanlı olmaması, uzmanlık gerektirmemesidir. Pratikte kolaylıkla uygulanabilen bu yöntemler doğada olan olayların matematiksel olarak ifade edilmesine dayalı olup en iyi çözümü bulma amacına yakın ve oldukça iyi çözüm verebilmektedir [2].

Meta sezgisel yöntemler arasında yaygın olarak aşağıdaki sürü optimizasyonu tabanlı yöntemler literatürde oldukça çalışılmaktadır:

- Parçacık sürüsü optimizasyonu [3]

- Yapay Arı Kolonisi Algoritmas1 [4]

- Karnnca Kolonisi Algoritmas1 [5]

- Arı Sürüsü Algoritması [6]

- Havai Fişek Algoritması [7]

Bunların dışında, biyolojik olaylardan esinlenerek geliştirilen algoritmalarda vardır [1]:

- Atmosfer Bulut Modeli

- Japon Ağaç Kurbağası Çağrısı

- Balık Sürüsü Algoritması

- Gen Oluşumu Algoritması

- Termit Kolonisi Optimizasyonu

Ayrıca, fizik ve kimya tabanlı olayların matematiksel ifadelerinden yola çıkılarak elde edilen algoritmalarda kullanılmaktadır [1]:

- Gen Oluşumu

- Kara Delik

- Merkezkaç Optimizasyonu

- Spiral Optimizasyon Algoritmas

- Su Döngüsü Algoritması

Bu çalışmada PID kontrolcü için optimum parametrelerin aranması amacıyla su döngüsü algoritması kullanılmıştır. Geleneksel olarak, birden fazla parametrenin olduğu problemlerde, tek bir uygunluk fonksiyonu kullanılarak arama yapılmaktadır [8]. Ancak, PID kontrolcünün her bir parametresinin uygulanan sistemin çıkışına etkisi farklı olduğundan farklı uygunluk fonksiyonları kullanılarak optimum değerlerin aranması daha doğru sonuçlar verecektir. Uygunluk fonksiyonları olarak, literatürde sıklıkla hataya bağlı birikim yapan performans fonksiyonları kullanılmıştır [9]. Bu amaçla yapılan bir çalışmada, uygunluk fonksiyonları ile iterasyon sayısı arasındaki ilişki deneysel olarak ortaya konmuştur [9].

Çalışmanın geri kalanı şu şekilde organize edilmiştir: Materyal ve yöntem ikinci bölümde anlatılmıştır. Deneysel çalışma sonunda elde edilen sonuçlar grafikler ve tablo olarak üçüncü bölümde verilmiştir. Son bölümde, değerlendirme yapılmıştır.

\section{Materyal ve Metot}

\subsection{Materyal}

Su döngüsü algoritması ile PID parametrelerinin optimizasyonu amacıyla bir simülasyon yazılımı kullanılarak bir DC motorun ikinci derece modeline sensör gürültüsü eklenerek, üzerinde farklı iterasyon sayılarında simülasyonlar yapılmıştır [10].

Kullanılan model Şekil 1'de verilmiştir. 


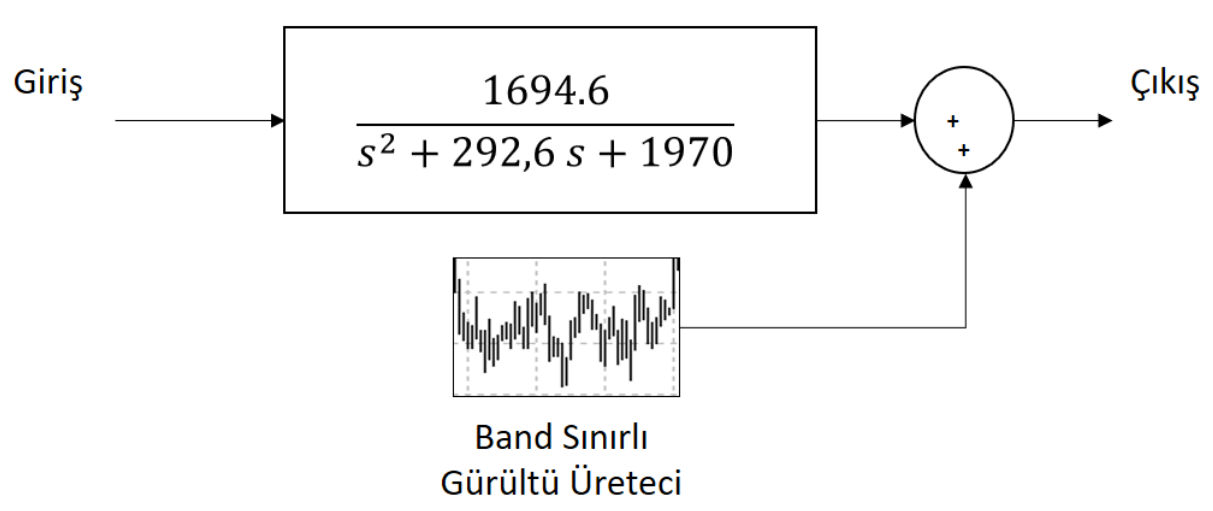

Şekil 1. DC motor modeli

\subsection{Doğada Su Döngüsü}

Su, doğada 1sı kaynaklı sürekli bir çevrim içerisindedir. Bu çevrim, okyanus ve denizlerde buharlaşma ile başlar, yükselen buhar birleşerek bulutları oluşturur. Bulutlar ısı kaybı kaynaklı yoğunlaşarak su damlacıklarını oluşturur. Su damlacıkları yağmurlar şeklinde yeniden yeryüzüne iner. Karaya düşen su, yer çekiminin etkisi ve akışkanlığı gereği sürekli deniz seviyesine doğru hareket eğilimindedir. $\mathrm{Bu}$ hareketinde birleşme eğilimi içerisinde olduğu müddetçe dereleri, nehirleri oluşturur ve ana hedef okyanus ve denizlere doğru akışını güçlendirerek sürdürür. Nihayetinde okyanus ve denizlere ulaşan su, döngüsünü tamamlar ve 1sı kaynağ1 olduğu müddetçe bu döngüsünü sürdürür.

\subsection{Su Döngüsü Algoritması}

Su Döngüsü Algoritması, doğadan esinlenilerek tasarlanan yöntemler arasında olup doğada suyun döngüsünde kullanmış olduğu akış, dönüşüm ve erozyon kurallarının matematiksel ifadelerinden yola çıkılarak elde edilen bir algoritmadır. Su döngüsü aşamaları Buharlaşma, Yoğunlaşma, Yağış, Erozyon, Akış gibi aşamalar içerir. Aynı zamanda bu döngü sırasında her aşama belirli bir mal oluşu da beraberinde getirmektedir. Suyun birleşmesi suyu büyütür. Buharlaşması ve Erozyon ise suyun küçülmesine sebep olur [2].

\subsection{SDA Matematiksel Modellemesi}

SDA’nda en küçük değişken değere "Yağmur Damlası" denir. Popülasyon tabanlı meta-sezgisel yöntemlerde optimizasyon için değişken değerlerine ait bir dizi oluşturulmalıdır. Bir N_var boyutlu optimizasyon probleminde, bir yağmur damlası N_var dizisidir ve şu şekildedir:

$$
\text { Yăgmur Damlası }=N_{\text {var }}=\left[x_{1}, x_{2}, \ldots, x_{N}\right]
$$

Algoritmanın başlayabilmesi için, matrisine denk $N_{\text {pop }} \times N_{\text {var }}$ boyutunda bir yağmur damlası popülasyonu oluşturulur. Bu nedenle, rastgele üretilen X matrisi şu şekilde verilir (satırlar nüfus sayısını, sütunlar ise değişken değeri sayısıdır)

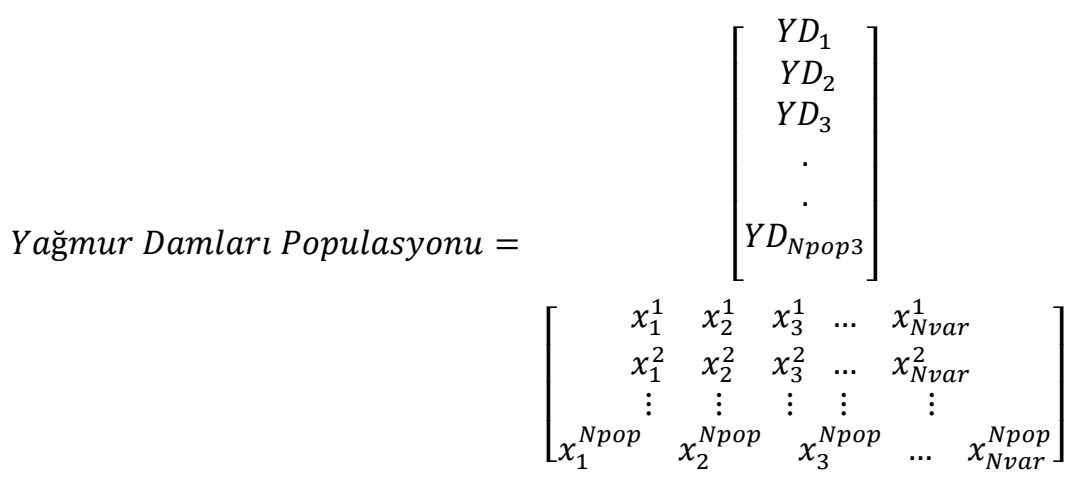

Karar değişkeni değerlerinin $\left(X_{1}, X_{2}, \ldots, X_{\text {var }}\right)$ her biri başlangıç noktası numarası veya sürekli ve ayrık problemler için dizi olarak gösterilebilir. Bir damlanın maliyeti (en düşük değer), ekonomik şekilde verilen maliyet fonksiyonunun bireyleri deniz ve nehirler olarak seçilir. Mutlak hedef deniz olduğundan denizin tek değeri bir olarak kabul edilir. Dolayısıyla, denklemde verilen $N_{s r}$ nehir sayısı (kendi belirlediğimiz ön değer) ve denizin toplam değeridir. Kalan değerler yağmur damlaları nehirlere veya doğrudan denize akabilecek değerlerden oluşur (5).

$$
C_{i}=\text { Maliyet }_{i}=f\left(x_{1}^{i}, x_{2}^{i}, x_{3}^{i}, \ldots, x_{N_{p o p}}^{i}\right)
$$

Burada $\mathrm{i}=1,2,3, \ldots, \mathrm{N} \_$pop 
$N_{s r}=$ Nehir Saylsl $+\underset{\text { Deniz }}{1}$

$N_{y d}=N_{p o p}-N_{s r}$

Akışkanın yoğunluğuna bağlı olarak damlaların nehirlere ve denize akışını oluşturulan denklem:

$N S_{n}$, belirli nehirlere veya denize akan akarsuların sayısıdır.

$N S_{n}=$ yuvarla $\left\{\left|\frac{\text { Maliyet }_{n}}{\sum_{i=1}^{N_{s r} \text { Maliyet }_{i}} \mid}\right| \times N_{y d}\right\}$

Burada $\mathrm{n}=1,2, \ldots N_{s r}$

Bir akışın sağlanabilmesi için yağmur birleşerek daha büyük değerleri oluşturması gerekir (nehir, deniz). Akarsuların kalan kısmı da denize doğrudan akabilir. Nehirler ve akarsular en düşük nokta olan Denize doğru akarlar. Nehre doğru olan akış koşulu:

$X \in(0, C \times d), \quad C>1$

Burada C, 1 ile 2 arasında ve 2'ye yakındır. Dolayısıyla $C=2$ şeklinde yakınsanır. Akış ve nehir arasındaki uzaklık (7) değeri, $(0$ ve $\mathrm{C} \mathrm{x}$ d)'nin arasındaki bir değer gelecektir. C>1 olduğu için akarsuların nehirlere doğru akışını gerçekleşir.

$X_{\text {akls }}^{i+1}=X_{\text {akls }}^{i}+$ rand $\times C \times\left(X_{\text {nehir }}^{i}-X_{\text {akls }}^{i}\right)$

$X_{\text {nehir }}^{i+1}=X_{\text {nehir }}^{i}+$ rand $\times C \times\left(X_{\text {deniz }}^{i}-X_{\text {nehir }}^{i}\right)$

(10) denklemindeki $d_{\text {max }}$ değeri sıfıra yakındır. Eğer, bir nehir ve deniz arasındaki mesafe yani $d_{\text {max }}$ 'tan az ise, nehrin denize ulaşacağı anlaşıllır ve denize ulaşırsa, buharlaşma işlemi gerçekleşir, biriken ve yoğuşmayı başaran buhar yağmur (yağmur damlası) olarak tekrar yağacaktır. $d_{\max }$ değeri en yüksek değerden başlayıp azalarak denize yakın en düşük deniz yoğunluğunu bu sayede, en az maliyetli yolu bulmuş olur.

$d_{\text {max }}^{i+1}=d_{\text {max }}^{i}-\frac{d_{\text {max }}^{i}}{\text { max iterasyon }}$

Buharlaşma uygun sıcaklıkta yoğunlaşarak yağmura olarak yağacaktır. Yeni yağmur damlaları birleşerek akarsuları meydana getirir. Yeni akarsuların konumlarını oluşturmak için aşağıdaki denklem kullanılır:

$X_{a k l s}^{y e n i}=L B+$ rand $\times(U B-L B)$

LB ve UB değerleri sırasıyla alt ve üst sınırlardır. En uygun yağmur damlaları doğrudan oluşan akış cazibeleri ile denize doğru akar. Diğer yağmur damlaları ise nehirlere veya doğrudan denize akabilecek akarsuları oluşturduğu varsayılmaktadır.

Doğrudan denize akan akarsular için algoritmanın daha hızlı yakınsama yapması için denklem (12) kullanılır. Bu denklem, kısıtlı problemler için uygulanabilir bölgedeki denize yakın olan değerlerin (optimum çözüm ile) yakınsayarak "doğrudan denize akan akarsu" oluşumunu teşvik etmeyi amaçlamaktadır.

$$
X_{\text {akls }}^{\text {yeni }}=X_{\text {deniz }}+\sqrt{\mu} \times \operatorname{randn}\left(1, N_{\text {var }}\right)
$$

Burada $\mu$, denize yakın arama bölgesi aralığını gösteren bir katsayıdır. Randn normal olarak dağıtılan rasgele sayıdır. $\mu$ değeri daha büyük seçilebilir, dolayısıyla uygulanan alan büyür ve "doğrudan denize akan dere" bulunma ihtimalini artırır. Aksi durumda "doğrudan denize akan dere" bulunma ihtimali düsşer. $\mu$ 'ya 0.1 değeri ön tanımlama olarak atanmıştır. Aynı zamanda matematiksel olarak $\mu$ terimi standart sapmayı ve buna bağlı olarak varyans kavramını da ifade etmektedir. Standart sapma ve varyans kullanılarak nihayi hedef deniz etrafında dağıtılır.

\subsection{PID Kontrol Sistemi}

Bir DC motor modeli kullanılarak PID optimizasyonu için aşağıdaki şekilde verildiği gibi bir sistem hazırlanmıştır. 


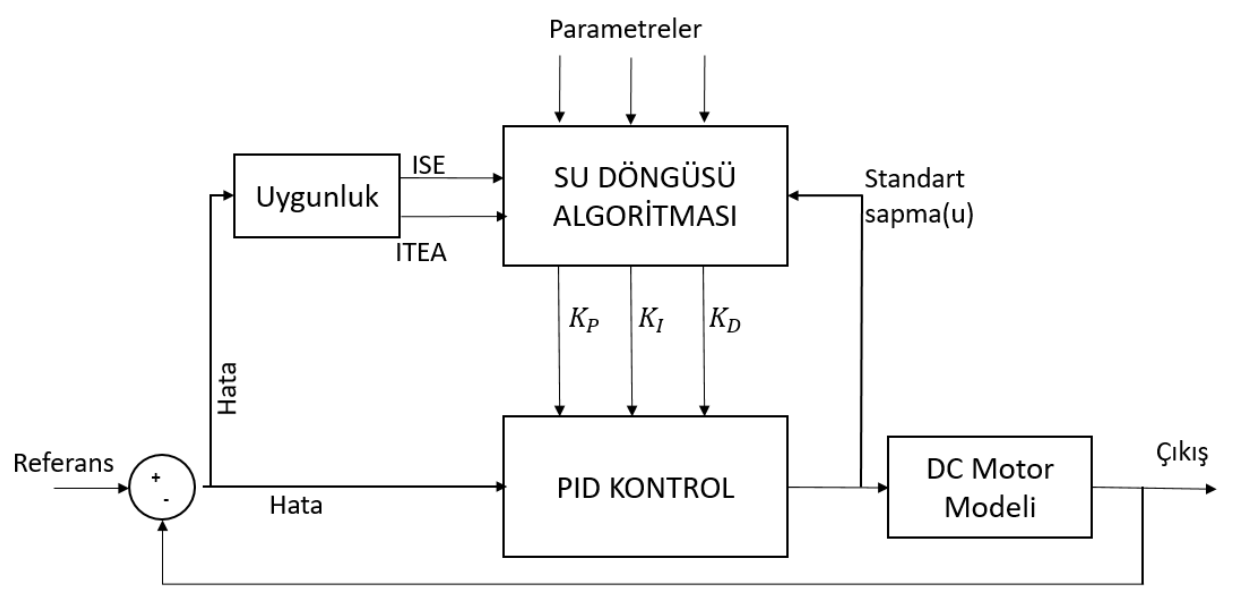

Şekil 2. Su Döngüsü Algoritması ile PID ayarlama için blok diyagram

\subsection{Su Döngüsü Algoritma Yazılımı Kuralları}

Su döngüsü algoritmasının değerlendirdiği akarsu, dereler ve nehirler değerleri algoritmanın belirlemiş kural ve sınırlarını ihlal edebilir. Bu metotta, algoritma 4 kural ile kısıtlanmış ve daha doğru değerlere yakınsanmıştır.

Kural 1: Herhangi bir uygulanabilir çözüm, herhangi bir uygulanabilir çözüm yerine tercih edilir.

Kural 2: Kısıtlamaların hafifçe ihlalini içeren (ilk yinelemede 0,01 'den son yinelemede 0,001 'e kadar) mümkün olmayan çözümler uygulanabilir çözümler olarak kabul edilir.

Kural 3: İki uygulanabilir çözüm arasında, daha iyi objektif fonksiyon değerine sahip olan tercih edilir.

Kural 4: İki olanaksız çözüm arasında, daha az kısıtlama ihlaline sahip olanı tercih edilir.

Birinci ve dördüncü kuralları kullanarak, doğrudan denize akan akarsuyun olabileceği bölgeler bulunur.

Üçüncü kuralı doğrudan denize akan akarsuyun olabileceği bölgelere yöneliktir.

Optimizasyon çözümlerinde, minimum kabul edilebilir uygulama sınırına ya da bu sınırın yakınına yakınsanır. Kural 2 ile akarsu ve nehirler sınırlara yakınsanır. Bununda da daha yüksek bir ihtimal ile denize ulaşabilir.

Yakınsama kuralı, son zamanlarda Meta-sezgisel algoritmalarda Yineleme sayısının fazlalığı, işlemin süresi açısından en iyi sonuç alınan kurallardandır.

\subsection{Su Döngüsü Algoritmasının Yazılım Adımları}

Matematiksel modellemede oluşturulan denklemlere göre SDA'nın adımları aşağıdaki gibi özetlenir:

$\checkmark$ Adım 1: SAA'nın başlangıç parametrelerini seçin: Nsr, dmax, Npop, max_iteration.

$\checkmark$ Adım 2: Rastgele başlangıç popülasyonu oluşturun ve denklemleri kullanarak ilk akışları (yağmur damlaları), nehirleri ve denizi oluşturun. (2), (4) ve (5).

$\checkmark$ Adım 3: Denklem kullanarak her bir yağmur damlasının değerini (maliyetini) hesaplayın. (3).

$\checkmark$ Adım 4: Denklemler kullanarak nehirler ve deniz için akış yoğunluğunu belirleyin. (6).

$\checkmark$ Adım 5: Akımlar Denklemi (8).

$\checkmark$ Adım 6: Nehirler Denklem kullanarak en yokuş aşağı yer olan denize akar (9).

$\checkmark$ Adım 7: Nehir konumlarını, Şekil 5'te gösterildiği gibi, en iyi çözümü veren bir akımla değiştirin.

$\checkmark$ Adım 8: Adım 7'ye benzer şekilde, eğer bir nehir denizden daha iyi bir çözüm bulursa, nehrin konumu denizle değiştirilir (Şekil 5).

$\checkmark$ Adım 9: (9) kullanarak buharlaşma durumunu kontrol edin.

$\checkmark$ Adım 10: Buharlaşma koşulu sağlanmışsa, yağmurlama işlemi denklemler kullanılarak yapılacaktır. (11) ve (12).

$\checkmark$ Adım 11: Denklem kullanarak kullanıcı tanımlı parametre olan d_max değerini azaltın. (10).

$\checkmark$ Adım 12: Yakınsama kriterlerini kontrol edin. Durdurma kriteri karşılanırsa, algoritma durur, aksi takdirde 5. Adıma dönün.

Yukarıda verilen adımların akış diyagramı Şekil 3'de yer almaktadır. 


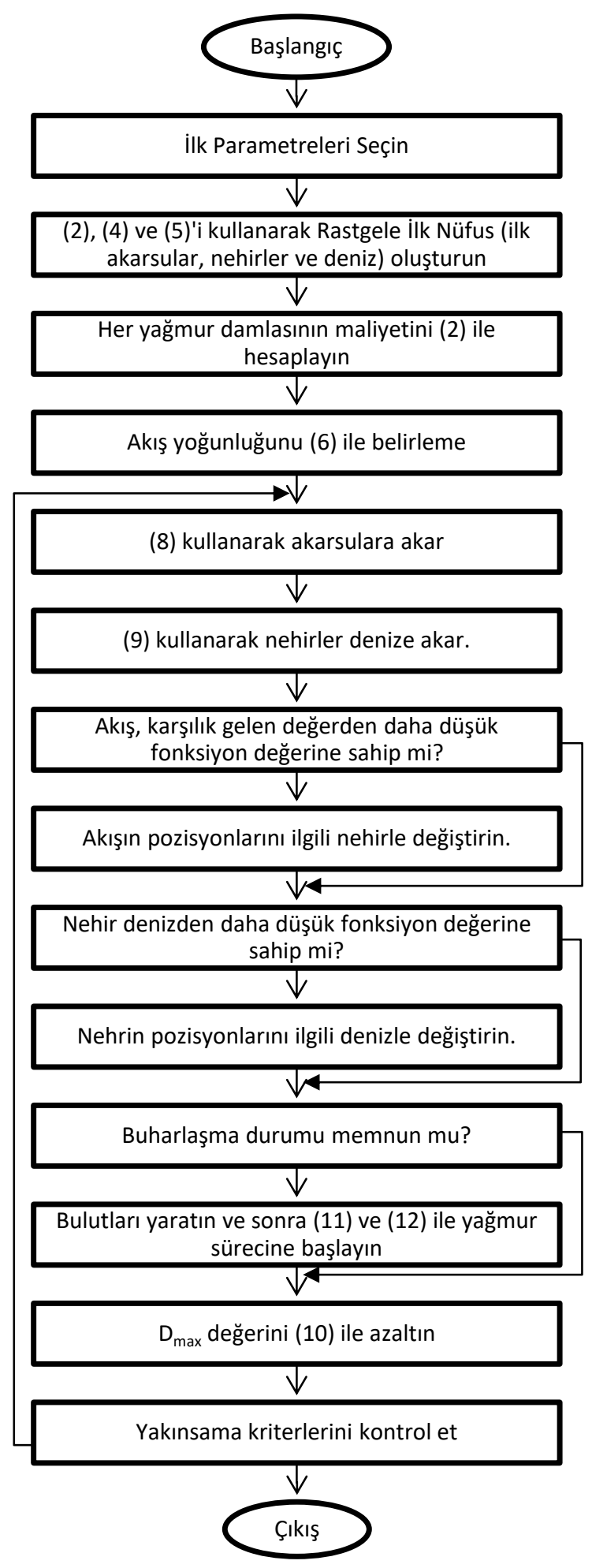

Şekil 3. Su döngüsü algoritması akış diyagramı 


\section{Araştırma Sonuçları ve Tartışma}

Deneysel çalışma için ilk başta sisteme uygulanacak PID kontrol parametre aralıkları $k_{\mathrm{p}}$ için $13-40, k_{\mathrm{i}}$ için 5-15, $k_{d}$ için $0.01-0.35$ olarak seçilmiştir. Sistemin referansı 8 olarak ayarlanmıştır. SDA iterasyon sayıları 20, 50 ve 100 belirlenmiş, su damlacıkları sayılar da 10,50 ve 100 olarak seçilmiştir. Bunların kombinasyonlarında yapılan simülasyonların süreleri de ölçülerek hazırlanan tablo aşağıda verilmiştir. Uygunluk fonksiyonları aşă̆ıdaki gibi seçilmiştir:

$k_{p}$ için ISE: $f p=\int e^{2}(t) d t$

$k_{i}$ için ITAE: $f i=\int t|e(t)| d t$,

kd için kontrol sinyalinin standart sapması:

$f d=\sqrt{\frac{\sum u(t)-\bar{u}(t)}{n-1}}$

Tablo 1 incelendiğinde 100 iterasyon ve 100 adet yağmur damlası ile toplam 10.000 simülasyon yapılarak ISE: 0.3238 ve ITEA: 0.764 değerleri 1134s'de elde edilmiştir.

50 iterasyon ve 50 adet yağmur damlası ile toplamda 2.500 simülasyon yapıldığında elde edilen sonuçlar ISE: 0.3439 ve ITEA: 1.0025 olarak ölçülmüş, simülasyon 240s sürmüştür.

20 iterasyon ve 10 adet yağmur damlası ile toplamda 200 simülasyon sonucu ISE 0.3706 ve ITEA 0.8438 sonuçları 28 s süren simülasyon sonunda ölçülmüştür.

Tablo 1. Deneysel çalışma sonuçları

\begin{tabular}{|c|c|c|c|c|}
\hline İterasyon Sayısı & $\begin{array}{c}\text { Yağmur } \\
\text { Damlası Sayısı }\end{array}$ & ISE & ITAE & $\begin{array}{c}\text { Simulasyon Süresi } \\
\text { (s) }\end{array}$ \\
\hline \multirow{3}{*}{20} & 10 & 0.3706 & 0.8438 & 28 \\
\cline { 2 - 5 } & 50 & 0.3704 & 0.8434 & 95 \\
\cline { 2 - 5 } & 100 & 0.3350 & 0.8672 & 236 \\
\hline \multirow{3}{*}{50} & 10 & 0.4633 & 0.8819 & 75 \\
\cline { 2 - 5 } & 50 & 0.3439 & 1.0025 & 240 \\
\cline { 2 - 5 } & 100 & 0.3966 & 0.8473 & 629 \\
\hline \multirow{3}{*}{100} & 10 & 0.3343 & 0.8682 & 136 \\
\cline { 2 - 5 } & 50 & 0.3723 & 0.8428 & 554 \\
\cline { 2 - 5 } & 100 & 0.3238 & 0.8764 & 1134 \\
\hline
\end{tabular}

Şekil 3'te 100 yağmur damlası 20 ve 100 iterasyonda çalıştırılarak elde edilen en iyi çıkış grafikleri yer almaktadır. 
European Journal of Science and Technology
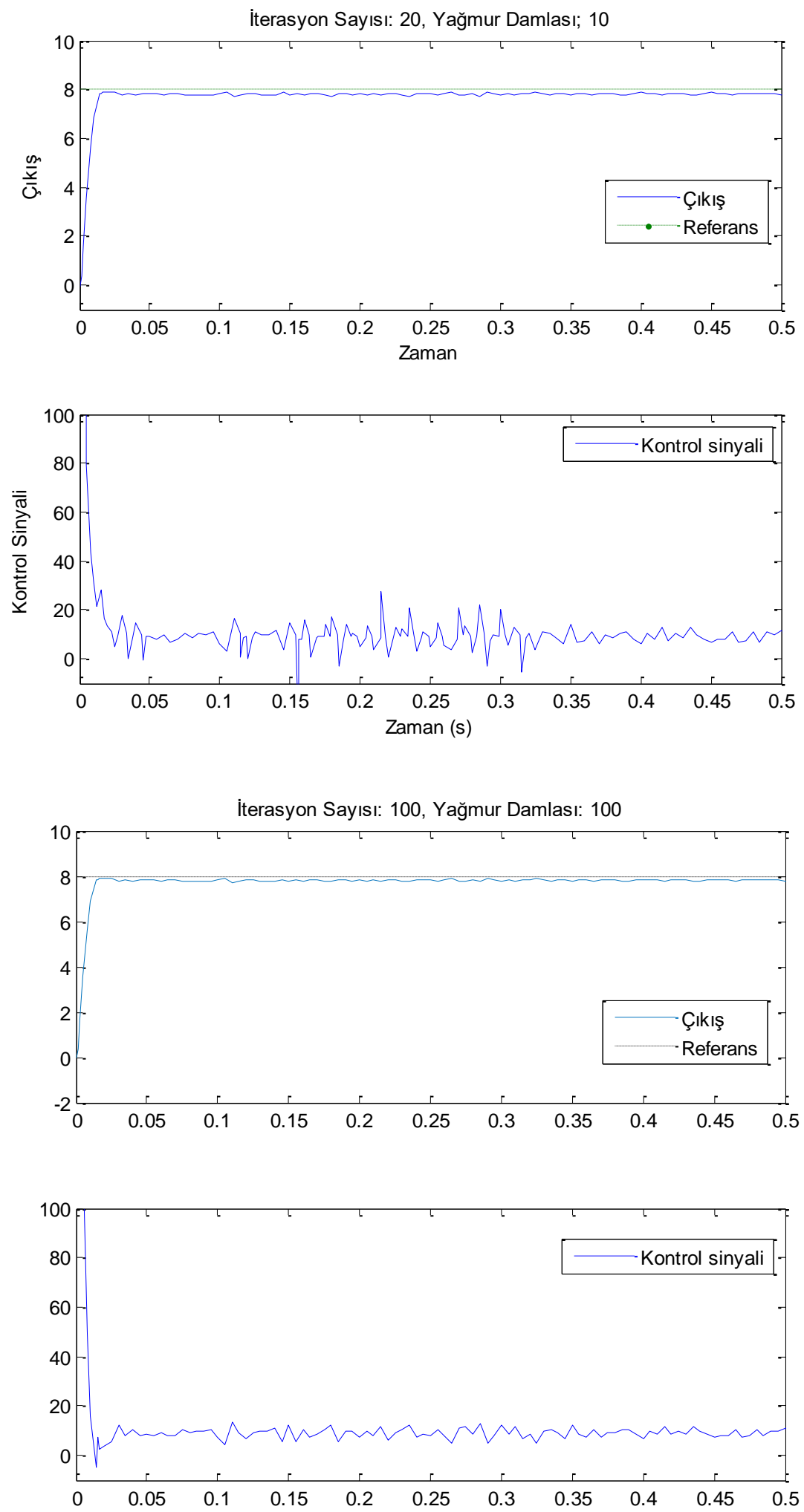

Şekil 3. Optimum PID parametreleri ile sistem çılkışı ve kontrol sinyalindeki değişimler

Yapılan deneysel çalışmada, seçilen uygunluk fonksiyonlarının iterasyon sayılarına göre değişimi Şekil 4'te verilmiştir. 
Avrupa Bilim ve Teknoloji Dergisi
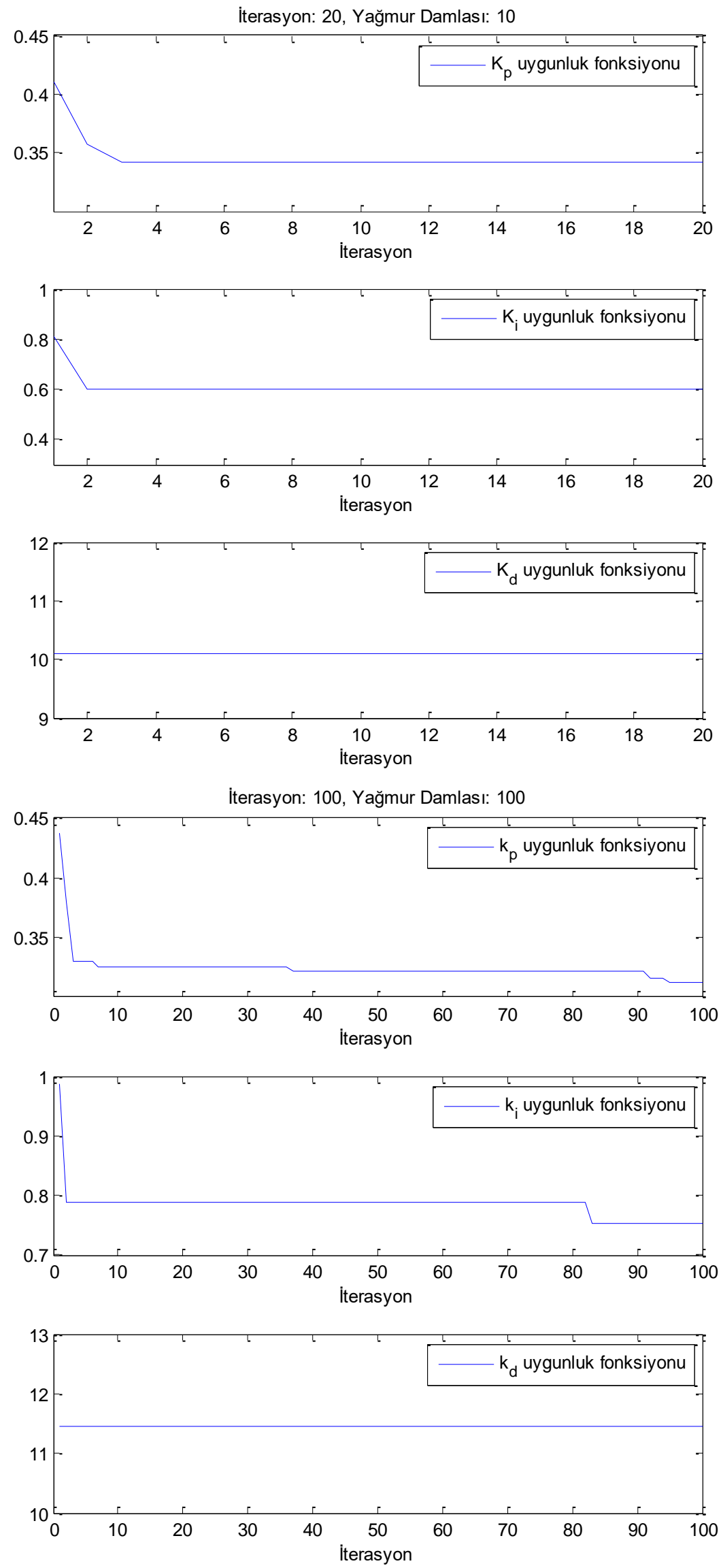

Şekil 4. Uygunluk fonksiyonundaki değissimler 


\section{Sonuç}

$\mathrm{Bu}$ çalı̧̧mada, optimum PID parametrelerinin aranması için su döngüsü algoritması kullanılmıştır. Her bir parametre için farklı yapıda uygunluk fonksiyonları, literatürde sıklıkla kullanılanlar arasından parametrelerin özelliklerine uygun olanlar seçilmiştir. Elde edilen sonuçlar değerlendirildiğinde, az sayıda yağmur damlası ve iterasyon sayısı ile başarılı sonuçlar elde edildiği görülmüştür. Bulunan parametreler ile sistem çalıştırıldığında kalıcı durum hatası gözlenmezken çıkışta aşım da oluşmamıştır. Sistem çıkışı $50 \mathrm{~ms}$ 'den kısa sürede referans değerinin \%95'ine ulaşmıştır. Bununla beraber, gürültülü olan sistem çıkışında kullanılan türev parametresi, gerçek sistemlerdeki kontrol uygulamalarında aşırı genlikli kontrol sinyali oluşturmasından dolayı ihmal edilirken, burada ortaya çıkan sonuç kontrol sinyalinin yeterli genlikle sitem çıkışındaki gürültüyü karşılayacak düzeydedir. Bu sonucun çıkmasındaki en önemli rolü türev parametresi için seçilen uygunluk fonksiyonudur.

Sonuç olarak, özelleştirilmiş uygunluk fonksiyonu su döngüsü algoritması, az sayıda iterasyon ile başarılı sonuçlar vermiştir. Bu yönü ile gerçek sistemlerin optimizasyonunda daha hızlı sonuç alınabilecek bir gelişme ortaya konmuştur.

\section{Kaynakça}

[1] Fister Jr, I., Yang, X. S., Fister, I., Brest, J. ve Fister, D. A brief review of nature-inspired algorithms for optimization. arXiv:1307.4186., Temmuz 2013

[2] Eskandar, H., Sadollah, A., Bahreininejad, A. ve Hamdi, M. Water cycle algorithm-A novel metaheuristic optimization method for solving constrained engineering optimization problems. Computers \& Structures, vol. 110, pp. 151-166, 2012.

[3] Gidemen, G. ve Furat, M. Parçacık değiştirmeli PSO algoritması - PID denetleyici optimizasyonu Üzerine uygulamasi. 2017 (IDAP) (pp. 1-6). IEEE., Eylül 2017, Malatya, Türkiye.

[4] Chatterjee, S., Kamboj, V. K. ve Jangid, B. PID Plus Second Order Derivative Controller for Automatic Voltage Regulator Using Linear Quadratic Regulator. In AI Techniques for Reliability Prediction for Electronic Components, pp. 262-287. IGI Global, 2020.

[5] Kumar, A. ve Sharma, R. A Nature Inspired PID like Fuzzy Knowledge-Based Fractional-Order Controller for Optimization. In Computational Network Application Tools for Performance Management, vol. 73, pp. 17-28. Springer, Singapore, 2020.

[6] Hekimoğlu, B. Robust fractional order PID stabilizer design for multi-machine power system using grasshopper optimization algorithm. Journal of the Faculty of Engineering and Architecture of Gazi University, vol.35(1), 165-180, 2020.

[7] Gong, C. Dynamic Search Fireworks Algorithm with Adaptive Parameters." International Journal of Ambient Computing and Intelligence (IJACI), vol.11(1), 115-135, 2020.

[8] Edaris, Z. L. Performance comparison of PID tuning by using ziegler-nichols and particle swarm optimization approaches in a water control system. Journal of Information and Communication Technology, vol.15(1), pp.203-224, 2020.

[9] Furat, M. ve Gidemen, G. PSO ile PID Parametrelerinin Optimizasyonunda Uygunluk Fonksiyonu Seçiminin Tekrarlama Sayısına Etkisi, Otomatik Kontrol Ulusal Toplantısı, TOK'2016, 29 Eylül - 1 Ekim 2016, Eskişehir.

[10]Furat, M.ve Eker, İ. Geliştirilmiş ikinci derece kayan kipli kontrol: teori ve deneysel uygulama. Mühendis ve Makina, vol. 57, pp.49-53, 2016. 